\title{
Sedimentary basin investigation using receiver function: an East African Rift case study
}

\author{
Nicola Piana Agostinetti, ${ }^{1,2}$ Francesca Martini ${ }^{3}$ and Joe Mongan ${ }^{3}$ \\ ${ }^{1}$ Department of Geodynamics and Sedimentology, University of Vienna, Austria.E-mail:nicola.piana.agostinetti@univie.ac.at \\ ${ }^{2}$ Geophysics Section, School of Cosmic Physics, Dublin Institute for Advanced Studies, Ireland \\ ${ }^{3}$ Tullow Oil plc, Applied Geophysics Team, Dublin, Ireland
}

Accepted 2018 September 27. Received 2018 August 20; in original form 2018 May 31

\begin{abstract}
S UMMAR Y
We apply receiver function (RF) methodology to map the geometry of a sedimentary basin along a $\sim 10$-km-long profile of broadband seismometers that recorded continuously for approximately 3 months. For a subset of the stations, we apply the Neighbourhood Algorithm inversion scheme, to quantify the geometry of basin bounding fault directly beneath the stations. We compare our results with active reflection seismic data and with the lithostratigraphy from a well located along the profile. We find that the $P$-to-s conversions from the sedimentsbasement interface (SBI), recorded in RF data sets together with information on intrabasin structures, are useful for obtaining high resolution images of the basin. The depth of the SBI derived from RF inversion is consistent (within $\sim 0.4 \mathrm{~km}$ ) with the estimates from active reflection seismic and the well data. This study highlights that analysis of teleseismic waveforms can retrieve relevant information on the structure of a sedimentary basin.
\end{abstract}

Key words: Statistical methods; Body waves; Crustal imaging.

\section{INTRODUCTION}

Sedimentary basins mapping plays a crucial role in the exploration of georesources throughout the world, from hydrocarbon exploitation to geothermal energy provision (Harvey 2014). Geophysical methods are successful in imaging and understanding the subsurface and consequently derisking subsurface investigations. The most widely applied exploration method is active reflection seismology because of its capability of retrieving high resolution images (Xie 2015). However, active seismics can be costly and as such, the industry is testing alternative low cost techniques to improve the position of the 2-D and 3-D seismic acquisition lines and focus the high-cost active seismic exploration programmes. Some of these methods are based on the passive recording of ambient noise and/or natural seismicity. The ambient noise techniques have been proved to be valuable mapping tools in an exploration reconnaissance context, because their low costs and their low environmental impact are advantageous (Martini et al. 2015).

Complementary to ambient noise measurements, receiver function (RF) analysis is a widely used tool in academia to image the seismic structure of the Earth's crust at different scales (Langston 1979), from the upper mantle (subduction zones, 40-80 km depth, Chiarabba et al. 2014; Piana Agostinetti \& Miller 2014) to shallow volcanic plumbing systems (0-5 km depth, Piana Agostinetti \& Chiarabba 2008). A teleseismic $P$-wave crossing a seismic discontinuity is partially converted into an $S$ wave (so called $P$-to-s or $P S$, phase). A RF is the time-series of such teleseismic Ps converted waves which contain information about the seismic discontinuities directly beneath a broad-band seismometer. Due to the near vertical incidence of teleseismic $P$ waves, the Ps phase is mainly recorded on the horizontal components of a seismometer. The $P$ wave, which contains information about the seismic source and the path between the earthquake and the station, is recorded on the vertical component (Langston 1979). De-convolving the vertical component from the horizontal ones isolates the Ps phases, allowing one to directly measure the time-delay between the direct- $P$ and the Ps arrival (Di Bona 1998). Such a time-delay is a function of the depth of the discontinuity at which the Ps has been generated and of the $S$-wave velocity $\left(V_{S}\right)$ profile above it. To obtain information on the seismic structure from the RF time-series, a geophysical inverse problem needs to be solved (Sambridge 1999). Solution of such a problem can be obtained using a forward solver that is able to map 3-D features beneath single seismic station, for example, dipping seismic discontinuities and/or anisotropic layers (Frederiksen et al. 2003).

It has been long recognised that RF data recorded at the surface of sedimentary basins present characteristic patterns such as coherent high amplitude reverberated phases (e.g. Clitheroe et al. 2000; Yu et al. 2015), or well-defined amplitude variation of the Ps phase with backazimuth (e.g. Lucente et al. 2005), given by the relevant $V_{S}$ discontinuity present at the sediment-basement interface (SBI, e.g. Clitheroe et al. 2000). The RF analysis has been applied in previous studies to investigate the seismic structure of sedimentary basins: from low resolution (e.g. kilometre-scale Julia et al. 2004; Srinivas et al. 2013) to high resolution analysis (e.g. 
200-300 m length-scale Zheng et al. 2005; Leahy et al. 2012; Licciardi \& Piana Agostinetti 2017). The RF data sets have been jointly inverted with surface waves dispersion curves to obtain the velocity profile within the sedimentary pile (Ma \& Clayton 2016), and also jointly interpreted with gravity measurements to reconstruct lithosphere flexure beneath foredeep sedimentary basins (Hetenyi et al. 2006). A sequential analysis of multiple Ps converted phases (so-called 'sequential $H-k$ stacking') is often applied for inferring sedimentary basin thickness (e.g. Yeck et al. 2013; Yu et al. 2015). Despite the many existing studies focusing on the elastic properties of sedimentary basins obtained using RF data (e.g. Mostafanejad \& Langston 2017; Liu et al. 2018), a detailed analysis of the RF data capability of reconstructing the geometry of a sedimentary basin is still lacking.

In this study, we use passive seismic data recorded (as part of a wider study of the structure and the seismicity in the area) by a densely spaced linear array of broad-band seismometers across a sedimentary basin within the East African Rift (EAR) to compute RF data-sets. The profile is parallel to a seismic line acquired within a 3-D active seismic survey and a well drilled to reach the crystalline basement lies at the profile midpoint. We analyse the first 0-2 s of the radial and transverse RF data sets to highlight the sediments signature. The RF data sets are then inverted for the position of the SBI and its lateral geometry. Results of the RF analysis are compared to the active seismic data recorded along the same profile and converted to depth, and with data from the well. Finally, we discuss our results in view of shallow-crustal exploration using passive seismics.

\section{GEOLOGICAL BACKGROUND}

The Kenya rift valley is part of the EAR system, a string of PlioceneMiocene age basins which run from the Afar Triple Junction in the Afar Depression southward through eastern Africa, along two main branches: the Gregory Rift and the Albertine Rift. The rift developed in the last $20 \mathrm{Myr}$, possibly related to the presence of a mantle plume, but its origin is still debated (Morley 1999).

The South Lokichar Basin is a NNW-SSE trending asymmetric half graben (with the main bounding fault on its western margin) within the Turkana Rift, itself a subbasin within the Great EAR System. The basin is approximately $70 \mathrm{~km}$ long and $35 \mathrm{~km}$ wide at its maximum extent and has a maximum depth of over $7 \mathrm{~km}$ (Tiercilin et al. 2004). The main fault, known as the Lokichar Fault, is relatively low angle and planar in section, although the dip varies considerably along strike from $12^{\circ}$ to $60^{\circ}$ (Morley 1999).

The gross basin stratigraphy can be described in terms of pre, syn and post-rift sequences. The pre-rift comprises of Pre-Cambrian crystalline metamorphic rocks. The overlying syn-rift consists of up to $5 \mathrm{~km}$ of fluvial-lacustrine sediments biostratigraphically dated as Lower to Middle Miocene. It also includes Miocene volcanicsphonolitic basalts dated at 12 to 16 million. The post-rift sequence, above the Miocene Unconformity, consists mainly of Pliocene to Holocene alluvium, fluvial and loose deposits (Morley 1999).

Exploration in the basin began with a well drilled by Royal Dutch Shell in 1992 which proved the presence of a good quality and mature source rock and good quality reservoir sands. This phase of exploration ended as the company assessed the results as noncommercial. Starting from 2008, Africa Oil Corp and subsequently Tullow Oil renewed the interest in exploration in this basin. Drilling began in 2012, which has led to a series of hydrocarbon discoveries, all close to the basin bounding fault.
As part of the exploration activities carried out in this basin, in 2014 a 3-D active seismic survey was acquired in the region with Tullow Oil as operator. During the acquisition activities in the region, the seismometers were also deployed parallel to two of the 3-D survey seismic lines (inline and crossline) as part of a wider study. The derived RF used in this study represent a secondary product of this dataset. The two $\mathrm{E}-\mathrm{W}$ and $\mathrm{N}-\mathrm{S}$ profiles cross at the location of a well. The lithostratigraphy from this well indicates that the crystalline basement is found at about $\sim 1900 \mathrm{~m}$ beneath the free-surface. Neogene sediments are found with intercalated volcanoclastics in the near-surface layer (Fig. 1).

\section{DATA AND METHODS}

We analyse teleseismic waveforms recorded at 47 broad-band seismic stations recording between September and November 2014 (Fig. 1). Stations have been deployed along a $\sim 10$-km-long linear profile that strikes normal to the local axis of the sedimentary basin. We select $186 M_{\mathrm{w}} \geq 5.0$ teleseismic events occurred between $30^{\circ}$ and $100^{\circ}$ of epicentral distance from the seismic network. The teleseismic RF are computed using a frequency-domain deconvolution (Di Bona 1998) which allows to estimate the uncertainties associated with each single RF. These uncertainties are used to build a weighted average of the RFs that come from similar backazimuthal direction (baz) and epicentral distance (dist), the so called bins. Both radial RF (R-RF) and transverse RF (T-RF) are computed and analysed for retrieving signal associated with a dipping seismic discontinuity. A frequency cut-off of $4 \mathrm{~Hz}$ is selected to investigate the shallow-crust structure (Gaussian parameter $a=8$ ). After RF computation, we visually inspect the RF to remove low quality traces (e.g. affected by monochromatic noise) and we retain from a minimum of 8 to a maximum of 69 RFs for each single station (with 25 stations with more than $20 \mathrm{RFs}$ ). The baz coverage is good, especially considering the short duration of the deployment.

As an example of RF data, we show the R-RF and T-RF data-sets as a function of the baz of the incoming $P$ wave, for the station EW27 (Figs $2 \mathrm{a}$ and b). RF are binned every $20^{\circ} \times 40^{\circ}$ in baz and dist, with a 50 per cent overlapping scheme. On the R-RF, a clear positive phase can be seen at about $1 \mathrm{~s}$, from $340^{\circ}$ to $170^{\circ}$ baz. The same phase has negative amplitude from $270^{\circ}$ to $290^{\circ}$. In the same time-window (about $1 \mathrm{~s}$ after the direct-P arrival), the T-RF displays an arrival which changes polarity twice along the baz axis, between $60^{\circ}$ and $120^{\circ}$ baz, and between $210^{\circ}$ and $310^{\circ}$ baz. The presence of these complementary patterns on R-RF and T-RF is a proxy of a dipping interface (Cassidy 1992). The absence of a complementary pattern in the amplitude of the direct-P arrival (at $0 \mathrm{~s}$ time-delay) is probably due to the very low $V_{S}$ in near-surface sediments (less than $1 \mathrm{~km} \mathrm{~s}^{-1}$ ), so that the $P$ wave ray path is turned almost vertical in the sedimentary cover and its projection along the Radial and Transverse plane is null. In principle, multiple Ps converted phases, arriving later in the RF data set, could add constraints on the position of the main velocity contrasts at depth. Unfortunately, the presence of a steep velocity contrast contributes to mask such arrivals and prevents their exploitation (Lucente et al. 2005).

We apply the angular harmonic decomposition method to improve the recognition of the main Ps pulses and their variations with baz direction (Frederiksen 2011; Piana Agostinetti \& Miller 2014; Park \& Levin 2016). A prominent positive pulse at about $1 \mathrm{~s}$ on the $k=0$ harmonics is coupled, with a positive arrival at the same arrival time, on the east-west component of the $k=1$ harmonics (Figs 2c and d). Such coupled phases are indicative of a shallow $V_{S}$ 

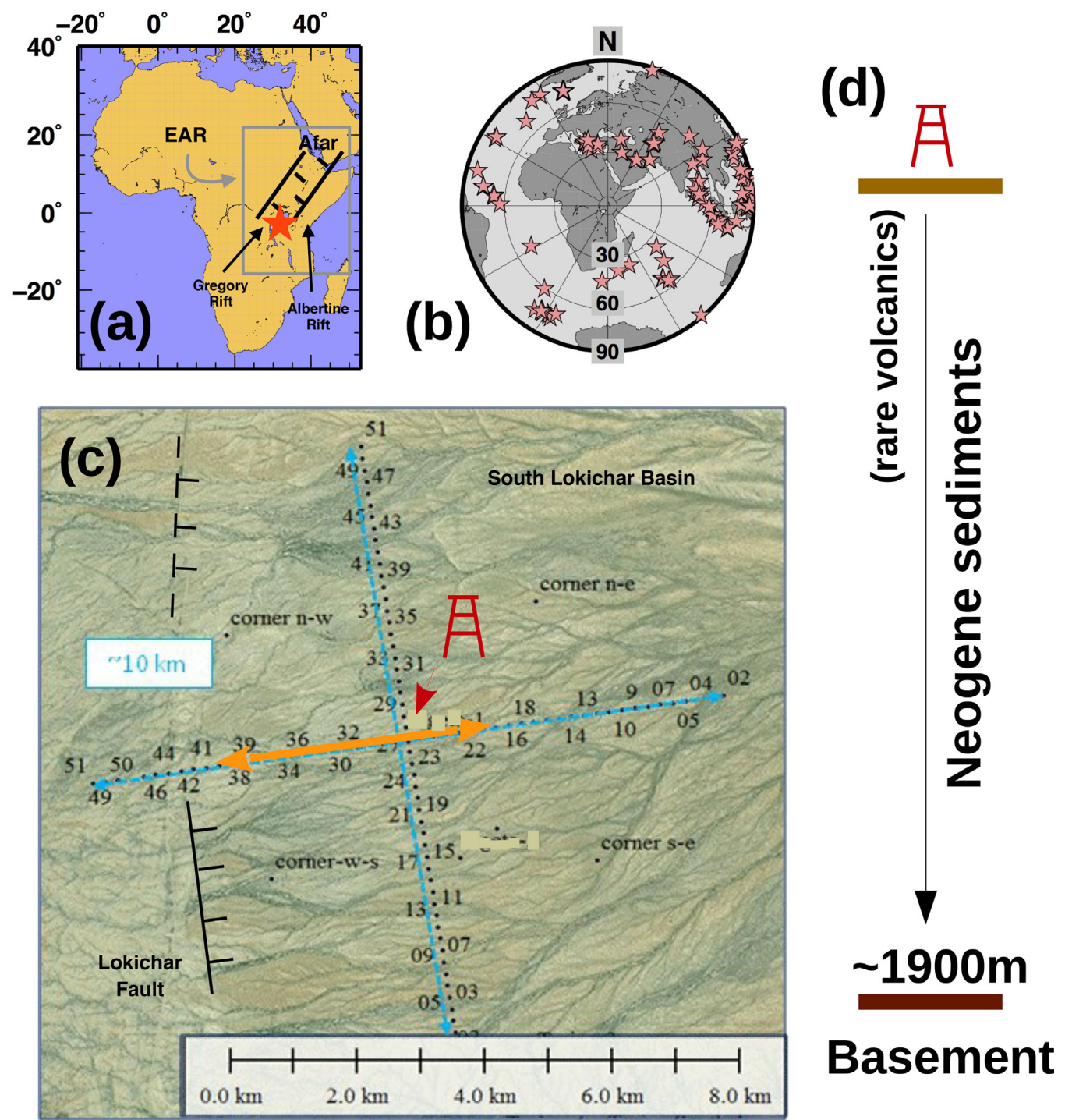

Figure 1. (a) Regional map with the position of the temporary seismic network (red star) and the sketched East African Rift (EAR). (b) Distribution of the teleseismic events $\left(M_{\mathrm{w}} \geq 5\right)$ occurred during the deployment of the temporary passive seismic network. (c) Geometry of the passive seismic network. Black dot indicate the location of a seismometer (numbers indicate station name). Blue lines defines the length of the two passive seismic profiles. Yellow line indicates the seismic stations used in the NA inversion. The position of the well is also shown. (d) Sketch of the lithostratigraphy at the well.

contrast, dipping towards east, or an interface between an isotropic and an anisotropic layer (Licciardi \& Piana Agostinetti 2016).

For the stations close to the emergence of the basin bounding fault, EW20 to EW40, we apply the Neighbourhood Algorithm (NA, Sambridge 1999), to independently retrieve the geometry of a dipping interface directly beneath each station. No multistation data processing is applied (e.g. as in Li \& Nabelek 1999; Rondenay et al. 2001; Langston \& Hammer 2001). Our approach ensures that coherent features between neighbouring stations are not process artefacts. The NA is a global search algorithm that produces robust estimates of the investigated parameters together with their uncertainties. Here we follow the implementation adopted in Lucente et al. (2005). We use the RAYSUM forward solver, a ray-shooting algorithm for tracing seismic phases (Frederiksen \& Bostock 2000) to compute synthetic RF generated from a one layer model separated from the underlying half-space by a freely oriented planar interface. This simplified parameterization can be used to repro- duce the main Ps pulses both on the R- and T- RF data set, avoiding the risk of overfitting the data, and to give first-order information about the geometry of the basin bounding fault. Due to the limited number of phases reproduced by our simplified parametrization, the inversion window is limited to $[-1 ; 5]$ s. Clearly, a more sophisticated inversion scheme could be applied, in a second analysis step, to improve the fit to the waveforms and to fully exploit the information contained in the RF data. The seven investigated parameters are: thickness of the layer, $V_{S}$ and $V_{P} / V_{S}$ in the layer and in the half-space, dip and strike of the interface. We sample $N_{\text {tot }}=$ 5100 models from $N_{\text {cells }}=100$ different regions of the model space (i.e. Voronoi cells) iterating the NA algorithm $N_{\text {iter }}=51$ times. We define the 'best-fitting' family as the suite of models for which the fit to the observed RF is no more than 10 percent larger than the fit obtained by the best-fitting model. To measure the robustness of our solution, we run the NA inversion using different $N_{\text {cells }}, N_{\text {tot }}$ and $N_{\text {iter, }}$, without finding any relevant differences in the results. 

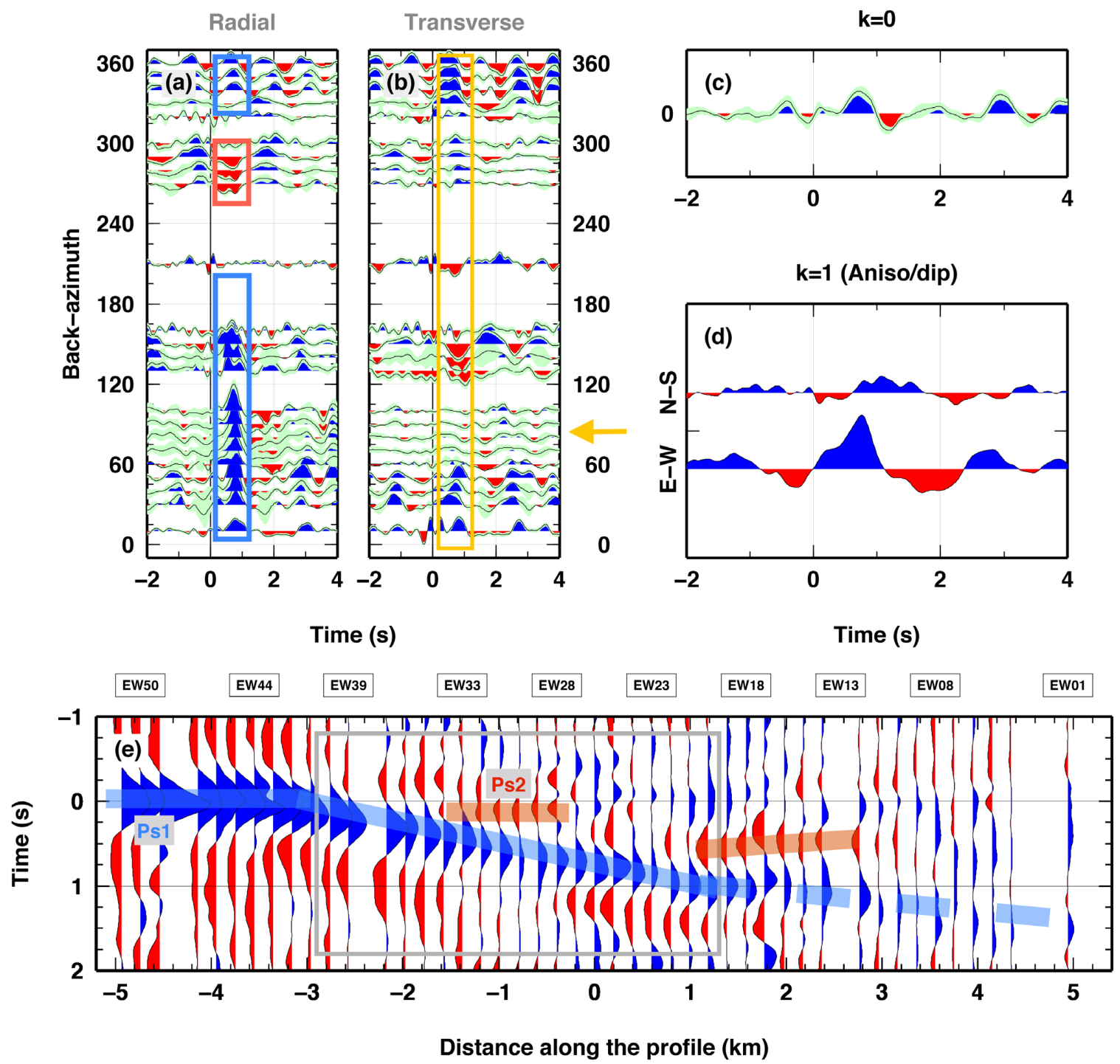

Figure 2. (a-d) Passive seismic data recorded at station EW27. (a) Binned R-RF and (b) T-RF data set as a function of the baz of the incoming $P$ wave. Blue (red) pulses indicate positive (negative) arrivals. A light-green area around the binned RF shows the $1 \sigma$ standard deviation obtained during the stacking process. Coloured boxes and a yellow arrow indicate phases and baz direction cited in the text. (c-d) The $k=0$ and $k=1$ harmonics of the RF data sets presented in panel $(\mathrm{a}-\mathrm{b})$. Colours as in panel $(\mathrm{a}-\mathrm{b})$. Light-green area on the $k=0$ harmonics indicates uncertainties obtained from a bootstrap analysis (e) Suite of $k=0$ harmonics for all the stations analysed in this study, projected along the east-west profile shown in Fig. 1. Zero-time delay corresponds to the free-surface. A grey box indicates the stations used in the NA inversion for mapping the sedimentary basin geometry. Blue and red lines indicate phases discussed in the text.

\section{RESULTS}

The main feature recorded by the RF data set in the first $4 \mathrm{~s}$ is a broad positive arrival ( $P S 1$ hereinafter, Fig. 2c ). Such pulse arrives at $0 \mathrm{~s}$ at the western end of the profile $(X=-5 \mathrm{~km})$, and it is flat to about $X=-3.2 \mathrm{~km}$ (between stations EW41 and EW42). From that point, the positive pulse starts to delay its arrival from 0 to $\sim 1.1 \mathrm{~s}$ at about $X=1.6 \mathrm{~km}$ (station EW18). The positive pulse is less clear for all stations east of EW17, however it can be traced almost to the end of the profile (station EW01) at about $1.5 \mathrm{~s}$. This characteristic arrival on the $k=0$ harmonics represents the so-called 'direct P' for station from EW50 to EW41 (which, in our rotation system ZRT, represents the arrival of the original $P$ wave). Afterward (towards east), it becomes the Ps converted phase at the SBI (Zheng et al. 2005). As highlighted above, the zero-amplitude direct-P arrival on the RF data set is likely given by the vertical ray path of the $P$ wave within the low-velocity sediments (Bao \& Niu
2017). Coherent arrivals between neighbouring stations can be also observed between $0 \mathrm{~s}$ and the $P s 1$ : those arrivals can be explained as due to intrabasin structures. Between EW32 and EW28, a clear negative phase (called Ps 2 hereinafter) can be seen between 0 and $0.2 \mathrm{~s}$, suggesting a near-surface decrease of $V_{S}$. Similar feature can be seen between EW22 and EW17, where we detect another broad negative arrival a few tenths of second above $P S 1$, which is probably related to a deep discontinuity within the basin.

To quantitatively investigate the geometry of the SBI, we perform the NA inversion for the 20 stations, where the $P_{S} 1$ signal is clearer (from station EW40 to EW20), and the R-RF and T-RF data set display the characteristic phases described for station EW27 (Figs 2a and b). The inversion results for station EW27 show that the main Ps phases are correctly reproduced on both R- and T- RF data set (Figs $3 \mathrm{a}-\mathrm{d}$ ). The single inverted parameters are well constrained, but not $V_{P} / V_{S}$ ratios and $V_{S}$ in the basement, due to the lack of the 

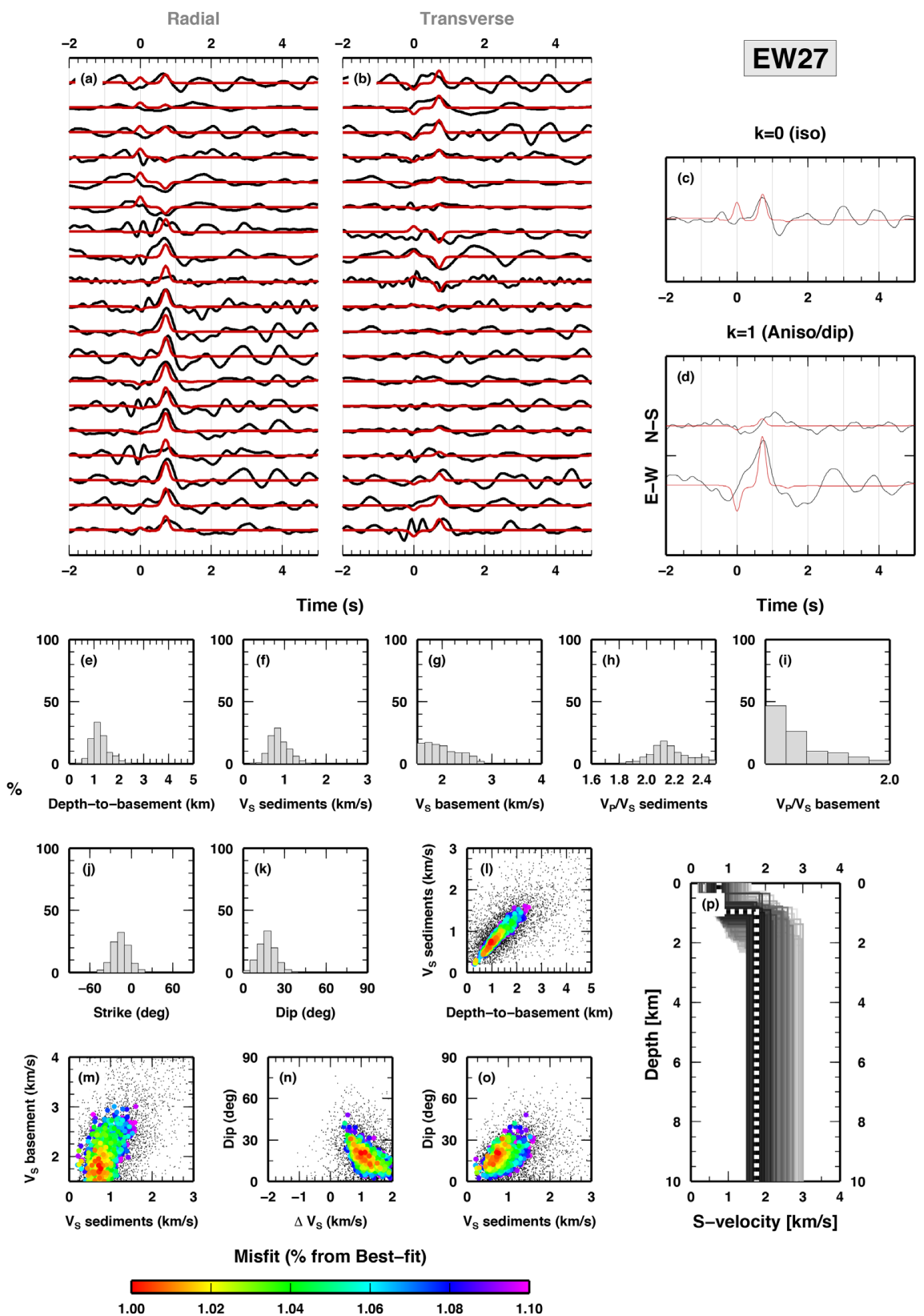

Figure 3. Inversion results for stations EW27. ( $a$ and b) Fit between observed and synthetic RF data set: radial (a) and transverse (b). synthetic data sets are computed using the best-fitting model found during the NA search. (c and d) Fit between observed and synthetic harmonics: $k=0$ (c) and $k=1$ (d). Synthetic harmonics are computed using the best-fitting model found during the NA search. (e-k) Frequency histograms of the investigated parameters considering only the models contained in the best-fitting family (see maintext for definitions). (1-o) 2-D distributions of the investigated parameters in the sampled models. Only models belonging to the best-fitting family are plotted. (p) 1-D $V_{S}$ profiles sampled during the NA search. A white dashed line indicates the best-fitting model.

relevant multiples phases (Figs 3e-k). Strong trade-offs exist between the depth of the SBI and the $V_{S}$ in the sediments, and between dip angle and $\Delta V_{S}$ (Figs 31-o), as expected (e.g. Cassidy 1992). Interpolating the results for all the stations, the geometry of the SBI can be easily retrieved as a $25^{\circ}$ dipping interface (Fig. $4 \mathrm{c}$ ), even if single station results display a certain degree of scattering (within one standard deviation) around the interpolated surface. Fault strike is almost in North direction, consistent through all stations, with the exception of station EW40 (Fig. 4h). For the single station results, dip angles vary between $15^{\circ}$ and $30^{\circ}$, with uncertainties between $5^{\circ}$ and $9^{\circ}$, consistently with the value found through interpolation (Fig. 4i).
We compare the results with the active seismic reflection line recorded along the same profile (depth processed) and with the SBI depth found at the well. Taking into account the limited number of phases modelled using our parametrization, the coherence between the predicted and observed RF is generally high for all stations (Fig. 5a). We observe that the depth of the SBI increases from station EW40 to station EW21, from 0.7 to $2.5 \mathrm{~km}$ depth (Fig. 5b). Coherent results are found between station EW34 and EW27, while estimates of SBI depth are more scattered for station EW26 to EW20. The average uncertainty on the retrieved SBI depth values can be quantified as $0.4 \mathrm{~km}$, larger towards the centre of the basin. The linear interpolation obtained for the SBI beneath all stations 

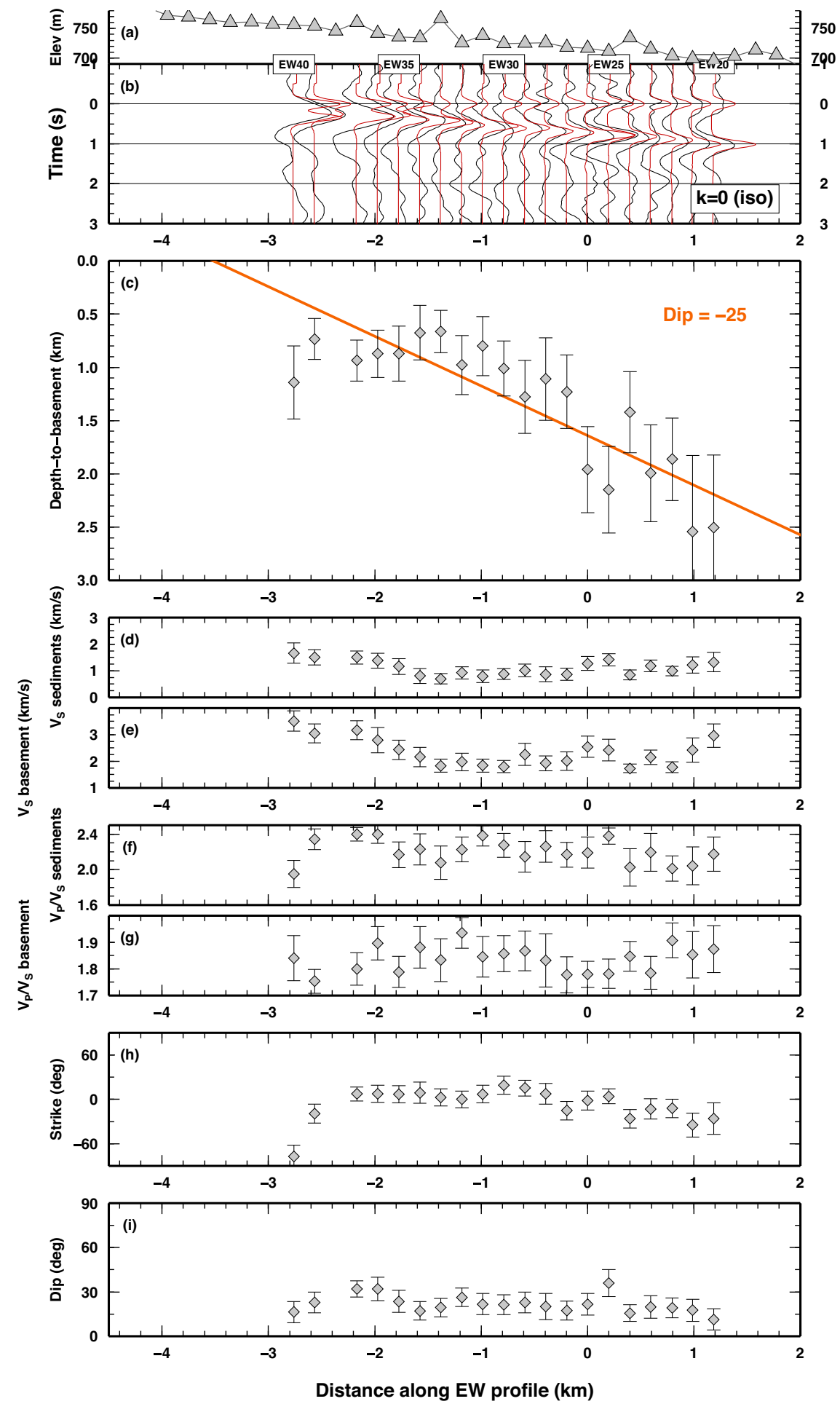

Figure 4. Summary of the results of the NA search for each single station. Data for each station are inverted separately (i.e. there is no constraint imposed from near-by stations). (a) Topography of the linear seismic array, in meters. (b) Fit between observed and synthetic $k=0$ harmonics. (c-i) Results of the NA search expressed in terms of mean (Grey diamonds) and standard deviation of the investigated parameter, considering only models belonging to the best-fitting family. In panel (c), the orange line indicates the linear fit obtained using data in Table S1, excluding station EW40 (which displays anomalous value of strike parameters).

is dipping $25^{\circ}$ towards east. We excluded EW40 from the linear interpolation, as it represents an outlier. In fact, for this station, the strike of the freely oriented interface is about $-70^{\circ}$, where for the other stations it is found to be between $-30^{\circ}$ and $30^{\circ}$ (Fig. 4h). If
EW40 is included in the interpolation, the dip angle decrease to $22^{\circ}$, while the depth at $X=0.0 \mathrm{~km}$ does not change significantly. The SBI depth is slightly shallower, with respect to the interpolated values, in the central portion of the profile, while it seems to be less 

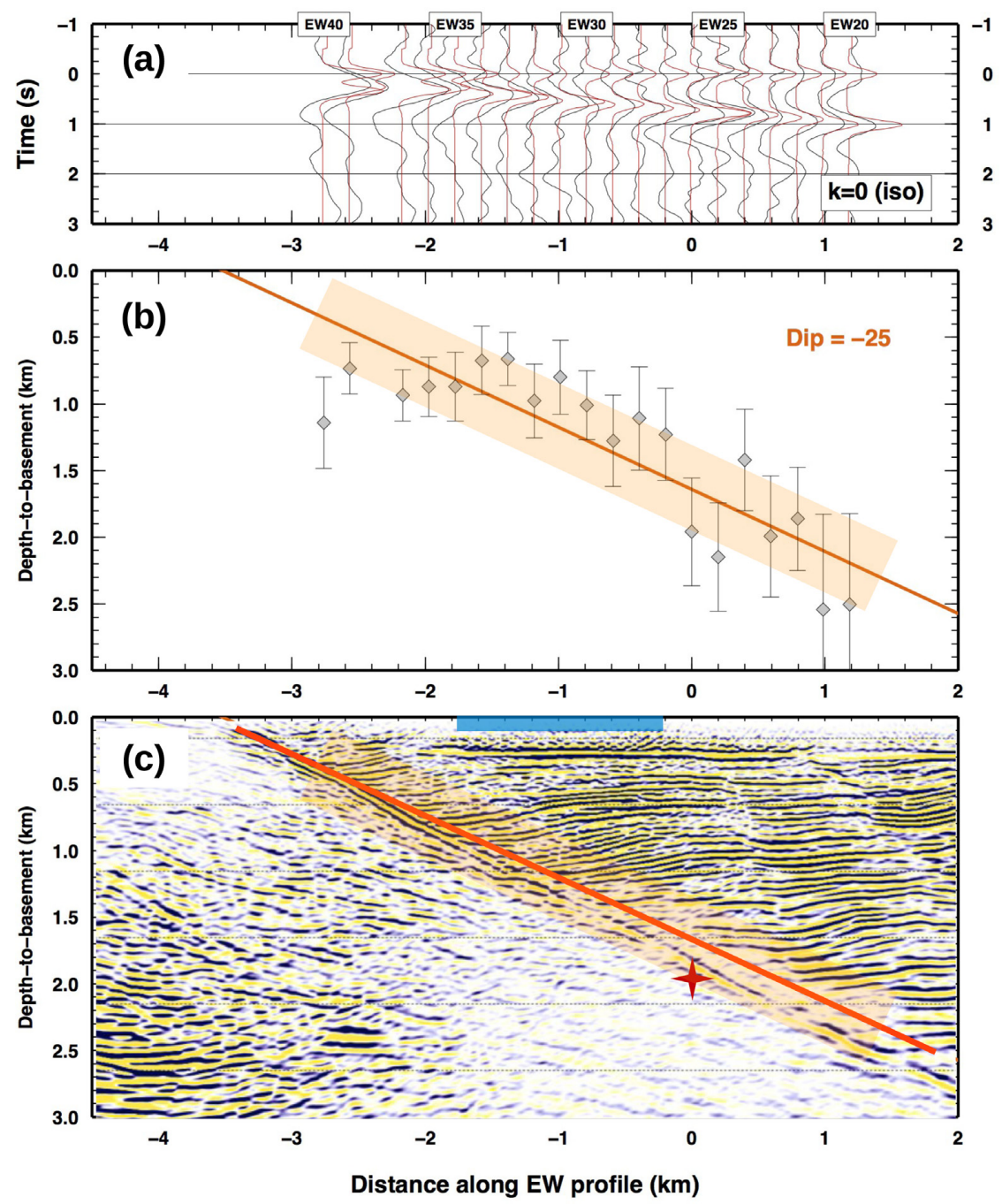

Figure 5. Comparison between the SBI interface obtained using RF data and the active reflection seismic image of the structure along the same profile, extracted from a 3-D multichannel seismic survey. (a) Fit between observed and synthetics RF data. Observed $k=0$ harmonics of the RF data set (black line) are plotted on synthetic $k=0$ harmonics computed using the best-fitting model found during NA inversion (red line). (b) Depth to basement for each single station, from NA inversion. Grey diamonds and error bars indicate the mean values and the uncertainties ( $2 \sigma$-interval) found at the end of the NA inversion, considering the family of sampled model with a fit not worst than 10 per cent of misfit of the the best-fitting model. The orange line displays the interpolated value of the depth of the basement using a least-square measure. The shaded orange area around the fit line defines the $\pm 0.4 \mathrm{~km}$ error estimate. (c) Passive versus active seismics data. Active seismic data obtained from a 3-D seismic survey, recorded along the same profile. The orange line is the interpolated interface, with its uncertainty (shaded area, as in panel 'b'). The red star shows the depth of the basement beneath station EW26 from the well data. The blue line at the surface indicates the position along the profile of an horizontal reflector at near-surface depth level, as seen from active seismic data.

coherent near the emergence of the basin bounding fault (i.e. where the SBI depth should be less than $0.5 \mathrm{~km}$ ).

The correspondence between the stronger dipping reflector seen by the active seismics and the linear trend inferred from passive seismic analysis is striking. At the well location, the difference between the obtained depth value and the observed basement depth is about $\sim 0.3 \mathrm{~km}$, which is within the estimated uncertainty. We note that the results obtained from station EW34 to EW27, which are shallower than the linear fit, correspond to an area where strong reflections occurred at the near-surface, possibly related to phase Ps 2 and the presence of a thick volcanoclastics layer. Finally, from $X=0$ to $1 \mathrm{~km}$, inversion results are more scattered: in this area, the active reflection 3 -D data indicate the presence of either a fault splay or an antithetic fault.

\section{DISCUSSION}

The RFs are used to investigate the topography of a Neogene sedimentary basin, exploiting the information contained in both the R-RF and the T-RF of 20 isolated stations deployed every $200 \mathrm{~m}$ along a profile normal to the local axis of the basin. To validate our results, the reconstructed geometry of the SBI is compared to active reflection seismic profile acquired along the same profile and to the depth of the basement obtained from the lithostratigraphy at the well-located midway along the profile. Our findings indicate that the depth of the SBI found from RF inversion is consistent within the $\sim 0.4 \mathrm{~km}$ uncertainty with the estimates from active seismics and well data. Depth estimates are more scattered where (i) depth of the SBI is relatively small with respect to the peak-frequency of the RF and (ii) where strong heterogeneity in the basin structure 
exist. In the first case, adopting an even higher frequency cut-off $(8 \mathrm{~Hz})$ could allow to investigate the portion of the fault closer to its emergence (e.g. Licciardi \& Piana Agostinetti 2017); in the second case, a multifrequency approach can be adopted to integrate lowfrequency information (Piana Agostinetti \& Malinverno 2018). The RF data sets obtained between 1 and $3 \mathrm{~km}$ away from the emergence of the basin bounding fault display characteristic pattern of $\mathrm{R}-\mathrm{RF}$ and T-RT ascribable to the presence of a strong and dipping velocity contrast. Such pattern can be used on a single seismic station to infer the SBI depth (Lucente et al. 2005). However, a linear array of seismic stations gives more robust uncertainty estimates and interpretations. In fact, the combined basement depth estimates and relative error bars obtained from RF data depict the area of highest probability for the SBI. The fault which represents the SBI as delineated in the active seismic data falls well within this area.

There are two main shortcomings in the analysis presented in this study. First, if the clear pattern on the R- and T-RF data set, described in Figs 2(a) and (b), is missing, results could be difficult to interpret, especially in case of isolated seismic stations. In fact, as shown in Fig. 4(c), scattering and uncertainties in the retrieved parameters could be large, preventing the correct identification of the basin bounding fault and its geometry, especially for the dip of the fault (Fig. 4i). Second, adopting our workflow, the fit to the observed waveforms could be limited, given the model parametrization and the simplified inversion scheme. As shown, visual inspection of the RF data sets indicates that high resolution information are in fact contained in passive seismic data (Fig. 2e). A more complex parametrization (e.g. two basin layers with gradient velocity inside) and an inversion scheme developed within a formal Bayesian framework, could be used to tackle this issue. However, this study highlights that even simplified data analysis of teleseismic waveforms can retrieve very relevant information on the geometry of a sedimentary basin.

Finally, the comparison of single and multistation analysis of teleseismic data demonstrates the potential of both isolated station and linear array. Multichannel analysis can improve the deconvolution and stability of the RF process, especially for RF data affected by strong reverberated phases (Langston \& Hammer 2001). In fact, in our case, for each teleseismic event, a source wavelet could be computed using the seismic stations outside the sedimentary basin (from EW42 to EW50). Such wavelet should be introduced in the RF processing for: (i) adding stability to the frequency-domain deconvolution and (ii) allowing the computation of the Z-RF, which integrate R-RF and T-RF with complementary information (e.g. Mostafanejad \& Langston 2017).

\section{CONCLUSIONS}

We use the passive seismic technique of the RF to map the geometry of the bottom of a sedimentary basin along a $\sim 10$ - km-long profile. We compare our results with the 3-D active seismic data recorded along the same profile and well data at the same location, to evaluate the performance of this seismic technique for shallow-crust investigation. We find that:

(1) the Ps conversions from the SBI are clearly recorded on both Radial and Transverse RF data sets, presenting a 'signature' characterized by amplitude-variable arrivals on Radial and reversedpolarity arrivals on Transverse RF, as a function of baz directions;

(2) the Ps conversions can be used to investigate the topography of the basin with uncertainties estimated, for each single measurement, in the order of $\sim 0.4 \mathrm{~km}$.
(3) Caution should be used in the analysis of RF data from sparse stations, if the characteristic signature of the SBI is not evident. Multistation analysis can improve the reconstruction.

(4) RF data sets also contain information on intrabasin structures, that can be exploited with more refined methodologies for obtaining high resolution images of the basin.

\section{ACKNOWLEDGEMENTS}

NPA thanks the Geophysics Section of the Dublin Institute for Advanced Studies for technical and administrative support during the last five years. This research has been partially conducted with the financial support of Science Foundation Ireland under Grant Numbers $14 / \mathrm{IFB} / 2742$ and $13 / \mathrm{RC} / 2092$. N.P.A. research is funded by Austrian Science Foundation (FWF) under Grant Number M2218N29. Authors would like to thank Tullow Oil and JV partners for the permission to publish these materials. Data request can be submitted to F.M. Figure are plotted using GMT (Wessel \& Smith 1998).

\section{REFEREN CES}

Bao, Y. \& Niu, F., 2017. Constraining sedimentary structure using frequencydependent $\mathrm{P}$ wave particle motion: a case study of the Songliao basin in NE China, J. geophys. Res.: Solid Earth, 122(11), 9083-9094.

Cassidy, J.F., 1992. Numerical experiments in broadband receiver function analysis, Bull. seism. Soc. Am., 82(3), 1453-1474.

Chiarabba, C., Giacomuzzi, G., Bianchi, I., Piana Agostinetti, N. \& Park, J., 2014. From underplating to delamination-retreat in the northern Apennines, Earth planet. Sci. Lett., 403, 108-116.

Clitheroe, G., Gudmundsson, O. \& Kennett, B.L.N., 2000. Sedimentary and upper crustal structure of Australia from receiver functions, Aust. J. Earth Sci., 47, 209-216.

Di Bona, M., 1998. Variance estimate in frequency-domain deconvolution for teleseismic receiver function computation, Geophys. J. Int., 134, 634646.

Frederiksen, A.W., 2011. Panel deconvolution of receiverfunction gathers: improved images via crosstrace constraints, J. geophys. Int., 184(3), 12751288.

Frederiksen, A.W. \& Bostock, M.G., 2000. Modeling teleseismic waves in dipping anisotropic structures, Geophys. J. Int., 141, 401-412.

Frederiksen, A.W., Folsom, H. \& Zandt, G., 2003. Neighbourhood inversion of teleseismic $p s$ conversions for anisotropy and layer dip, Geophys. J. Int., 155, 200-212.

Harvey, C., 2014. Best Practices Guide for Geothermal Exploration. IGA Service GmbH, Bochum University of Applied Science, .

Hetenyi, G., Cattin, R., Vergne, J. \& Nabelek, J.L., 2006. The effective elastic thickness of the india plate from receiver function imaging, gravity anomalies and thermomechanical modelling, J. geophys. Int., 167(3), $1106-1118$.

Julia, J., Herrmann, R.B., Ammon, C.J. \& Akinci, A., 2004. Evaluation of deep sediment velocity structure in the New Madrid Seismic Zone, Bull. seism. Soc. Am., 94(1), 334-340.

Langston, C.A., 1979. Structure under Mount Rainier, Washington, inferred from teleseismic body waves, J. geophys. Res., 84(B9), 4749-4762.

Langston, C.A. \& Hammer, J.K., 2001. The vertical component P-wave receiver function, Bull. seism. Soc. Am., 91(6), 1805.

Leahy, G.M., Saltzer, R.L. \& Schmedes, J., 2012. Imaging the shallow crust with teleseismic receiver functions, Geophys. J. Int, 191(2), 627-636.

Li, X.Q. \& Nabelek, J.L., 1999. Deconvolution of teleseismic body waves for enhancing structure beneath a seismometer array, Bull. seism. Soc. Am., 89, 190-201.

Licciardi, A. \& Piana Agostinetti, N., 2016. A semi-automated method for the detection of seismic anisotropy at depth via receiver function analysis, Geophys. J. Int., 205(3), 1589-1612. 
Licciardi, A. \& Piana Agostinetti, N., 2017. Sedimentary basin exploration with receiver functions: seismic structure and anisotropy of the Dublin basin (Ireland), Geophysics, 82(4), KS41-KS55.

Liu, G., Persaud, P. \& Clayton, R.W., 2018. Structure of the northern los angeles basins revealed in teleseismic receiver functions from shortterm nodal seismic arrays, Seismol. Res. Lett., 89(5), 1680-1689, .

Lucente, F.P., Piana Agostinetti, N., Moro, M., Selvaggi, G. \& Di Bona, M., 2005. Possible fault plane in a seismic gap area of the Southern Apennines (Italy) revealed by receiver functions analysis, J. geophys. Res., 110(B4), doi:10.1029/2004JB003187.

Ma, Y. \& Clayton, R.W., 2016. Structure of the los angeles basin from ambient noise and receiver functions, Geophys. J. Int., 206(3), 16451651.

Martini, F., Davi, R., Doherty, J. \& Mongan, J., 2015. Ambient noise to estimate depth to basement: case studies from East Africa basins, First Break, 33(2), 57-63.

Morley, C.K., 1999. Marked along-strike variations in dip of normal faults the Lokichar fault, N. Kenya rift: a possible cause for metamorphic core complexes, J. Struct. Geol., 21(5), 479-492.

Mostafanejad, A. \& Langston, C.A., 2017. Velocity structure of the northern mississippi embayment sediments, part II: Inversion of teleseismic P-wave transfer functions, Bull. seism. Soc. Am., 107(1), 106-116.

Park, J. \& Levin, V., 2016. Anisotropic shear zones revealed by backazimuthal harmonics of teleseismic receiver functions, Geophys. J. Int., 207(2), 1216-1243.

Piana Agostinetti, N. \& Chiarabba, C., 2008. Seismic structure beneath Mt Vesuvius from receiver function analysis and local earthquakes tomography: evidences for location and geometry of the magma chamber, Geophys. J. Int., 175(3), 1298-1308.

Piana Agostinetti, N. \& Malinverno, A., 2018. Assessing uncertainties in high-resolution, multi-frequency receiver function inversion: a comparison with borehole data, Geophysics, 83(3), KS11-KS22,

Piana Agostinetti, N. \& Miller, M.S., 2014. The fate of the downgoing oceanic plate: insight from the Northern Cascadia subduction zone, Earth planet. Sci. Lett., 408, 237-251.

Rondenay, S., Bostock, M. \& Shrag, J., 2001. Multiparameter twodimensional inversion of scattered teleseismic body waves, J. geophys. Res, 106(12), 30795-30807.
Sambridge, M., 1999. Geophysical inversion with a neighbourhood algorithm - I. Searching a parameter space, Geophys. J. Int., 138, 479-494.

Srinivas, D., Srinagesh, D., Chadha, R.K. \& Ravi Kumar, M., 2013. Sedimentary thickness variations in the Indo-Gangetic foredeep from inversion of receiver functions, Bull. seism. Soc. Am., 103(4), 2257-2265.

Tiercilin, J., Potdevin, J., Morley, C.K., Talbot, M., Bellon, H., Rio, A., Gall, B.L. \& Vetel, W., 2004. Hydrocarbon potential of the meso-cenozoic Turkana depression, northern Kenya. I. Reservoirs: depositional environments, diagenetic characteristics, and source rock-reservoir relationships, Marine Petrol. Geol., 21, 41-62.

Wessel, P. \& Smith, W.H.F., 1998. New, improved version of the generic mapping tools released, EOS, Trans. Am. geophys. Un., 79, 579.

Xie, C.G., 2015. Applications of tomography in oil-gas industry. Part 1, in Industrial Tomography, pp. 591-632, Woodhead Publishing.

Yeck, W.L., Sheehan, A.F. \& Schulte-Pelkum, V., 2013. Sequential H-k stacking to obtain accurate crustal thicknesses beneath sedimentary basin, Bull. seism. Soc. Am., 103, 2142-2150.

Yu, Y., Song, J., Liu, K.H. \& Gao, S.S., 2015. Determining crustal structure beneath seismic stations overlying a low velocity sedimentary layer using receiver functions, J. geophys. Res., 120, 3208-3218.

Zheng, T., Zhao, L. \& Chen, L., 2005. A detailed receiver function image of the sedimentary structure in the Bohai Bay Basin, Phys. Earth planet. Inter, 152(3), 129-143.

\section{SUPPORTING INFORMATION}

Supplementary data are available at $G J I$ online.

Table S1. Depth of the basement beneath each single station from EW20 to EW40, $X$ represent the distance along the profile, with station EW26 in the central position $(X=0)$. Depth is considered from the free-surface (no topographic correction is included, but station differ no more then $60 \mathrm{~m}$ in altitude).

Please note: Oxford University Press is not responsible for the content or functionality of any supporting materials supplied by the authors. Any queries (other than missing material) should be directed to the corresponding author for the paper. 